\title{
SUJEITO E HISTÓRIA:
}

\section{sobre o conceito marxista de classes sociais ${ }^{1}$}

\section{Rodne de Oliveira Lima ${ }^{2}$}

Resumo: Este artigo examina a categoria das classes sociais na teoria social crítica. Analisa, sucessivamente, o conceito na obra de Marx e em autores do marxismo clássico e contemporâneo. Ao final, estuda o caso especial das classes sociais no campo.

Palavras-chaves: classes sociais; marxismo; capitalismo; classes sociais rurais.

\begin{abstract}
This article intends to examine the social class category on critical social theory. The analysis is focused primarily on the Karl Marx concepts and then successively on the others Marxists classics and contemporary authors. At the end, the article studies the special case of social class on the rural areas.
\end{abstract}

Key words: social class; Marxism, capitalism, rural social class.

\section{Introdução: $O$ conceito marxista de classes sociais}

\footnotetext{
${ }^{1}$ Este artigo é uma versão modificada do capítulo 4 da dissertação de mestrado do autor, intitulada “Agricultura e Modernização Capitalista”, apresentada ao Programa de Pós-Graduação em Sociologia do Instituto de Filosofia e Ciências Humanas da Universidade Estadual de Campinas em dezembro de 1997.

${ }^{2}$ Doutor em Sociologia pela Universidade de São Paulo. Professor-Adjunto do Departamento de Ciências Sociais da Universidade Estadual de Londrina.
} 
Em torno do conceito de classe social a tradição marxista protagonizou extensa polêmica teórica, gerando constantemente proposições divergentes e contraditórias sobre o tema. Em parte, ela se deve a inexistência nos textos de Marx de uma longa sistematização sobre o tema, sendo necessário aos estudiosos contemporâneos o recurso àquelas passagens, onde indireta e por vezes marginalmente Marx a ele se referiu, mas também podemos atribuí-la à dinâmica das transformações ocorridas no modo de produção capitalista, que demandaram reiteradamente a atualização dos sentidos atribuídos ao conceito.

Apenas no epílogo d'O Capital encontramos uma passagem na qual Marx nos apresenta sua definição conceitual do termo. A despeito da interrupção do manuscrito e do caráter incompleto que dela decorreu, o trecho pelo qual o autor inicia o assunto é bastante ilustrativo dos elementos a partir dos quais sua análise do modo de produção capitalista articula-se com o estudo das classes sociais:

Os proprietários de simples força de trabalho, os proprietários de capital e os proprietários de terras, cujas respectivas fontes de receitas são o salário, o lucro e a renda do solo, ou seja, os operários assalariados, os capitalistas e os latifundiários, formam as três grandes classes da sociedade moderna, baseada no regime capitalista de produção. ${ }^{3}$

Desse modo, o conceito de classe social em Marx surge com um duplo significado. De um lado, como categoria analítica, indica um movimento, uma relação social, expressando o conteúdo genérico-abstrato das determinações comuns e gerais sob as quais, nas sucessivas épocas históricas, o trabalho produtor de valor foi realizado sob a égide da dominação política e exploração econômica. De outro, como categoria histórica

\footnotetext{
${ }^{3}$ MARX, K. O Capital : crítica da economia política - vol. I - livro primeiro - tomo 2. São Paulo: Abril Cultural, 1984. p. 99.
} 
particular, indica uma estrutura social e sujeitos localizados no interior da produção capitalista, expressando o sentido específico-particular pelo qual a dominação e exploração dessa época histórica opõem-se àquelas próprias das sociedades estamentais e de castas e delas se distingue. Com esse último sentido, Marx utiliza o termo em diferentes passagens d'O Capital, referindo-se às forças motrizes da sociedade. Posteriormente Lênin insistirá nesse sentido do conceito, esclarecendo como para o marxismo, a constituição de uma classe é definida a partir de suas relações com os meios de produção:

Chamam-se classes, grandes grupos de homens que se distinguem pelo lugar que ocupam num sistema historicamente definido de produção social; por sua relação, na maioria das vezes fixada e consagrada pela lei com os meios de produção; por seu papel na organização social do trabalho; e, conseqüentemente, pelos meios que têm para obter parte da riqueza social de que dispõe e o tamanho desta. As classes são grupos de homens dos quais um pode apropriar-se do trabalho de outro em virtude da posição diferente que ocupa num regime determinado da economia social. ${ }^{4}$

No capítulo sobre a fórmula trinitária, esse sentido enunciado por Lênin já fora utilizado por Marx. Vale indagar as implicações de sua aceitação: nele, Marx define as classes fundamentais da sociedade a partir da propriedade dos elementos fundamentais da produção - elementos que são descritos aqui como fontes independentes da produção do valor, o que evidentemente constituiria um paradoxo da interpretação marxista da produção capitalista, se tomado o sentido estrito dessa afirmação. Mas a compreensão das questões com as quais Marx manejava na análise da fórmula trinitária pode relativizar o significado dessa distinção: se é um paradoxo identificar terra, capital e força de trabalho como fontes independentes do valor, no entanto é correto afirmar que a 
propriedade desses elementos da produção possibilita a coexistência de formas heterogêneas de apropriação de diferentes parcelas do valor na produção. A fórmula assim, indica um processo social, não um dado - salário, lucro e renda da terra, por um lado, referindo-se às condições de distribuição do produto do valor; por outro, força de trabalho, capital e propriedade fundiária indicando as condições de distribuição dos meios de produção. ${ }^{5}$

Duas conseqüências metodológicas resultam disso. Em primeiro lugar, o estudo das classes converte-se em síntese explicativa da sociabilidade capitalista, só podendo ser compreendido após a exposição da essência (livro I) e do conjunto da aparência (livro II) da produção. Em segundo lugar, na sua exposição o problema da identidade social é posto de imediato. Se Marx afirma a identificação das três grandes classes na sociedade capitalista em torno das posições que estas ocupam na produção, isso significa que capitalistas, assalariados e proprietários fundiários constituem-se classes fundamentais do modo de produção capitalista, em oposição ao caráter intermediário que outras características, originárias de variações nas formações sociais capitalistas tais como qualificação, posição hierárquica e grandeza de salário - ocasionam na identidade social dos produtores. De todo modo, importa apreender como o conteúdo do conceito, em ambos os casos, remete-se à identidade histórica concreta dos sujeitos e da estrutura social na qual interagem.

\section{Formulações do marxismo contemporâneo}

\footnotetext{
${ }^{4}$ LÊNIN, V.I. Una gran iniciativa. Cf. STAVENHAGEN, R. Classes Rurais na Sociedade Agrícola. São Paulo: Loyola, 1979. p. 30.
} 
Convém relativizarmos a abordagem que realizamos. Entre os autores marxistas contemporâneos, muitas outras interpretações prosperaram, relacionando o problema às transformações históricas do capitalismo e às filosofias sociais correntes. As obras de Althusser e Thompson são dois exemplos do que afirmamos. O primeiro, referindo-se aos aparelhos ideológicos de Estado, abriu campo à crítica do conceito, influenciando a afirmação de Poulantzas segundo a qual, as lutas de classe não transcorrem no campo das estruturas, mas das práticas sociais; o segundo, situando seu questionamento à noção leninista de classes sociais, recolocou o problema de relacionar o papel das estruturas e da ação dos indivíduos na determinação do contexto das situações históricas concretas. Ambos, entretanto, atualizaram o conceito de classes sociais que empregavam privilegiando os problemas particulares com que lidavam. Marcelo Ridenti, a partir da análise de Perry Anderson, aponta precisamente os limites das obras desses dois pensadores, demonstrando como Althusser incorre numa abordagem estática da história - não chegando a explicar como as lutas de classes, que interpreta como efeito das estruturas, poderiam transformá-las - enquanto Thompson, em sua solução simplificada da história, reduz o resultado das relações contraditórias entre as classes a mera soma de vontades individuais:

[Para Anderson] (...) Althusser e Thompson cairiam em erros opostos: o primeiro por identificar experiência à mera ilusão, desconhecendo-a como parte integrante do real; o segundo por identificar experiência, discernimento e aprendizado, deixando de lado a mistificação em que muitas vezes se envolve essa experiência (...) A forma como cada um desses autores enquadrou a História - 'processo sem um sujeito'

\footnotetext{
${ }^{5}$ FAUSTO, R. Marx: Lógica e Política : investigações para uma reconstituição do sentido da dialética tomo II. São Paulo: Brasiliense, 1987.
} 
(Althusser), 'prática humana autônoma'(Thompson) - seria latentemente a histórica $(\ldots)^{6}$.

(...) importa recuperar aqui a proposta de Anderson de não separar os fatores objetivos dos subjetivos, as imposições do MP [modo de produção] das ações voluntárias humanas (de classe) para a (re) produção, reforma ou eventual superação do capitalismo. O MP capitalista (implicando uma contradição entre FP [forças produtivas] e RP [relações de produção]), e as classes sociais que o constituem estão totalmente imbricados, não como dados estanques e pré-estabelecidos, mas como um dar-se em movimento (des) contínuo. $(. . .)^{7}$.

A crítica de Anderson e a afirmação final de Ridenti remetem o debate conceitual ao estudo da trajetória social das classes. Se for verdade que, segundo as leis estruturais do desenvolvimento capitalista, as classes fundamentais da sociedade tendem a polarizar-se em duas, sendo a propriedade fundiária subordinada ao capital no decorrer do processo histórico, não é essa a forma que possuem. Ao contrário, aparecem como inúmeras polarizações pelas quais expressam as contradições originadas da concorrência capitalista que, ao par com a oposição fundamental entre capitalistas e proletários gera conflitos entre grupos internos a essas grandes classes. José Arthur Giannotti ressalta a esse respeito o caráter secundário dessa polarização: os grupos no interior das grandes classes não se confundem com as classes, já que, mesmo estando em conflito por força da concorrência capitalista todos ainda se vinculam à produção na forma geral de capitalistas ou trabalhadores assalariados, disso resultando que se negue a validade da noção de frações postuladas por Poulantzas, já que as classes não se constituem como

\footnotetext{
${ }^{6}$ RIDENTI, M. Classes Sociais e Representação. São Paulo, Cortez, 1994. (coleção Questões de Nossa Época, v. 31). p. 52

${ }^{7}$ Id. Ib., p. 54.
} 
dado, mas como identidade dos processos sociais. ${ }^{8}$ É na dinâmica das lutas sociais que podemos localizar concretamente a posição dos grandes grupos na produção e a constituição de uma consciência social que os identifique como classes. O duplo sentido do termo em Marx readquire aqui sua unidade como desenvolvimento dialético que permite apreender a totalidade da vida social.

A distinção baseada na obra de Luckács entre as noções de classe em si e classe para si tornou corrente nas fileiras do marxismo a elaboração de uma concepção do conceito de classes sociais, que ao contrário dos postulados luckasianos resultava numa abordagem não-dialética da história. Entretanto, almejamos utilizá-la no sentido original de que era provida, expressando a totalidade do processo social. Se classe em si e classe para si expressam diferentes aspectos de existência econômica e de organização política dos produtores em torno das posições fundamentais na sociedade capitalista, seus significados podem ser mais bem apreendidos em termos de correspondência que de complementação: as lutas de classe não decorrem de uma polarização abstrata na produção, nem as classes existem nas lutas sociais, mas o conceito de classe social expressa em si a relação social que as constitui, a saber, a violência originária que resulta na separação fundamental entre força de trabalho e meios de produção. Identidade e representação fundem-se no conceito como expressão do fenômeno social total a que ele se refere:

(..) É esta a questão da relação das classes, no seio do movimento dialético de sua constituição, enquanto divisão social que é o fundamento desta démarche. As classes não se constituem em si, nem mesmo para si, mas para as outras. $(. . .)^{9}$.

\footnotetext{
${ }^{8}$ GIANNOTTI, J.A. Trabalho e Reflexão : ensaios para uma dialética da sociabilidade. 2.ed. São Paulo: Brasiliense, 1984.

${ }_{9}^{9}$ OLIVEIRA, F. O Elo Perdido : classe e identidade de classe. São Paulo, Brasiliense, 1987. p.11.
} 
Como expressão genérico-abstrata, o conceito indica que a existência das classes supõe alguma forma de exploração econômica e de dominação política, segundo as quais as relações de sociabilidade encontram-se mediadas por um equivalente geral que encarna o pressuposto da violência e da expropriação na forma do duplo monopólio da força e dos meios de produção. Refere-se assim, antes a uma condição de existência que a alguma classificação formalmente pressuposta na investigação.

\section{Classe e identidade social no capitalismo contemporâneo}

Tomado com o significado que ora precisamos, o conceito de classe social requer sua confrontação com a teoria do valor trabalho, que inaugura os fundamentos da teoria social de Marx. De tal confronto emergem os problemas centrais para os quais a teoria marxista contemporânea procurou elencar respostas por meio da atualização do conceito marxiano: de um lado, as múltiplas polarizações através das quais se manifestam as relações de oposição motivadas pela concorrência entre diferentes setores de uma mesma classe, indicam-nos como os vínculos em torno dos mecanismos de distribuição da riqueza social engendram uma condição particular de alienação na constituição histórica das classes capitalistas que aparecem de forma cambiante como portadoras de possibilidades simultâneas de aliança e de conflito; de outro, a inexistência de uma identificação unívoca entre o processo de trabalho produtivo e a constituição da classe operária mostra-nos quão sutil é a diferença entre os elementos de determinação fundamental e secundária no processo real de constituição das classes, e nos conduz à análise da formação das classes intermediárias na estrutura da sociedade 
capitalista. Ao contrário de Bob Carter para quem o caráter produtivo do trabalho das classes médias resultava da separação entre propriedade e função capitalista, transfigurada na personalidade da gerência ${ }^{10}$, temos em mente como para Marx a identificação do capitalista como membro de uma classe fundamental da sociedade resultava de sua condição de sujeito improdutivo na produção. Nesse sentido, a formulação de uma teoria das classes sociais para o capitalismo contemporâneo exige o enfrentamento da questão dos lugares na produção capitalista e, ao mesmo tempo, a compreensão do processo global de produção ao qual se aplica, cujo fundamento consiste na teoria do valor.

Ruy Fausto apresenta-nos a constituição da classe dos trabalhadores assalariados sob a perspectiva que retro enunciamos. De início, o autor salienta como pertence a essa classe fundamental da produção capitalista - trabalhadores produtivos e improdutivos, tornando-se impróprio definí-la exclusivamente em função da relação de assalariamento. Devemos notar como a identidade de classe, na passagem que citamos de Marx, encontra-se definida negativamente em relação à propriedade dos meios de produção força de trabalho e salário em oposição a posse de capital e ao rendimento do lucro. Fausto conclui, desenvolvendo a lógica marxiana de investigação, que os trabalhadores autônomos, aqueles que não se confrontam diretamente com o capital no mercado de trabalho, não pertencem à classe dos trabalhadores assalariados, a despeito de que outras categorias de trabalhadores improdutivos, tais como funcionários de bancos e do comércio, nela estejam inseridos, uma vez que são portadores apenas de mera força de trabalho em oposição àqueles primeiros, que com ela portam também certo conjunto mínimo de meios de produção. Ademais, no que diz respeito à constituição da

\footnotetext{
${ }^{10}$ Cf. RIDENTI, M. Op. cit.
} 
consciência de classe, os diferentes níveis de qualificação de salário e de poder decisório no processo produtivo a partir de certo limite também tendem a acarretar a perda das determinações de classe do trabalhador assalariado, mesmo quando se trata de um trabalhador produtivo ${ }^{11}$. Desse modo se esclarece como a constituição da identidade das classes no capitalismo resulta da seqüência dos diferentes momentos de identidade - a determinação econômica fundamental da condição de classe em si -, diferença - os efeitos das determinações secundárias relativas à posição hierárquica e salarial no mundo do trabalho - e contradição - oriunda dos efeitos de venda da força de trabalho e das relações sociais dela originadas - através dos quais se realizam as formas da sociabilidade capitalista. ${ }^{12}$

O caso especial das classes intermediárias ilustra precisamente esse processo. De fato, a formação das classes intermediárias na estrutura social capitalista supõe uma forma de rearranjo particular dos momentos referidos, do qual resulta uma identidade social desprovida da contradição essencial que opõe entre si as classes fundamentais da produção. A esse respeito, Fausto compara os exemplos das classes de produtores mercantis simples e da classe média de funcionários burocratas, demonstrando como, no primeiro caso, não chega a se constituir a polarização fundamental pela qual a identidade social daqueles produtores resultaria determinada pelas contradições capitalistas, e como, no segundo, essa polarização tornou-se resolvida em termos de uma universalidade real-ilusória. Quanto aos burocratas, isso se deve a característica

\footnotetext{
${ }^{11}$ Amparados nesse fundamento do conceito de classe social que aqui analisamos, rejeitamos as interpretações sobre a estrutura agrária capitalista que generalizam as diversas posições de classe elencando-as como formas de assalariamento disfarçado na produção, e que não levam em consideração o significado do movimento modificador das relações de trabalho no campo sobre a identidade de classe dos sujeitos sociais. Para exemplo: ver PRADO JUNIOR, C. A Questão Agrária. São Paulo: Brasiliense, 1979.

${ }^{12}$ FAUSTO, R., op. cit.
} 
peculiar de que sua renda provém de uma distribuição de segundo grau, cuja repartição não se encontra definida pela concorrência, mas pela mediação do Estado, simultânea à ausência de uma determinação que os faria identificar-se às classes dominantes no capitalismo, a de possuidores dos agentes de produção. Em relação aos produtores mercantis simples, o caráter intermediário de que são providos relaciona-se a nãocorrespondência da sociabilidade de que são portadoras ao núcleo da produção capitalista:

(...) Os pequenos produtores "independentes" representam uma "classe" que é suporte de relações do nível da circulação simples. A relação entre o estatuto desse grupo em relação às classes em sentido pleno deve ser buscada na relação entre a circulação simples e a circulação do capital, no interior do modo de produção capitalista. Como vimos, a circulação simples existe como camada de sentido "negada" no interior do sistema - a sua verdade é a da aparência (negada) do sistema - e as representações que se constroem a partir dela são representações ilusórias, verdadeiras só na medida em que representam a aparência enquanto aparência. É a partir daí que se deve pensar a significação dos grupos que suportam relações de produção simples, no interior de uma sociedade dominada pelo modo de produção capitalista. Sem dúvida, as relações (simples) que eles suportam não são as relações aparentes do sistema enquanto tais, a verdade das relações que os suportam é a de serem relações de produção simples - embora negadas pelo sistema - e as representações que se constroem a partir destas relações enquanto representações dessas relações não são ilusórias. Entretanto, essas classes são negadas pelo capital, no sentido de que as relações que as constituem são relações mais "fracas" do que as do "núcleo" do modo de produção - já simplesmente no plano da inércia das classes, o único que tratamos aqui - e o seu destino depende das relações dominantes, as desses núcleos. (...). ${ }^{13}$

\footnotetext{
${ }^{13}$ FAUSTO, R., op. cit., p. 238-9.
} 
Buscando relacionar os diversos tipos de classes intermediárias presentes no capitalismo contemporâneo, o autor enumera quatro espécies resultantes das formas de constituição de seu caráter intermediário:

a) as classes originadas da produção mercantil simples, já referidas, cujos membros se caracterizam por serem produtores de mercadorias improdutivas, porque nãosubsumidos ao modo de produção capitalista;

b) as classes de trabalhadores improdutivos interiores ao modo de produção capitalista, mas que não se defrontam com o capital, como é o caso dos funcionários do Estado e dos empregados domésticos;

c) as classes constituídas por trabalhadores produtivos cujas determinações que os vinculavam ao proletariado foram perdidas, tais como no caso dos funcionários de gerência que desempenham parte da função capitalista na produção;

d) as classes formadas por profissionais liberais, que se caracterizam por não produzirem mercadorias nem venderem sua força de trabalho, mas sim o serviço, produto imaterial de seu trabalho. ${ }^{14}$

Francisco de Oliveira reitera parcialmente as posições de Fausto acerca das classes intermediárias no capitalismo e acrescenta a elas uma análise sobre as

\footnotetext{
14 É conveniente distinguirmos precisamente essa última classe intermediária dos produtores de mercadorias improdutivas. Enquanto os primeiros vendem o produto de seu trabalho sem, no entanto incorporarem-se completamente ao núcleo da produção capitalista, nem sofrerem determinação essencial de sua dinâmica, estes últimos possuem determinada pela dinâmica do núcleo capitalista a extensão de suas atividades e comercializam o valor de uso de sua força de trabalho convertida em objeto de consumo imediato, na forma do caráter concreto de seu trabalho (o serviço). A relação não-salarial que caracteriza o trabalho do prestador de serviço autônomo realiza-se mediante a propriedade dos meios de produção, e lhe atribui uma identidade particular no interior da produção capitalista, a de produtor independente de um produto imaterial. Convém notar como - em comparação com os produtores assalariados de serviços caso no qual a imaterialidade do trabalho reside estritamente em sua determinação formal, que impede o serviço a despeito da mediação do capitalista empreendedor de circular como mercadoria, fazendo-o aparecer sem qualquer descontinuidade em relação ao processo de trabalho como trabalho imaterial - no caso dos produtores autônomos a determinação imaterial do serviço é real, pois inexiste qualquer ocorrência de compra de força de trabalho. Cf. FAUSTO, R., op. cit.
} 
transformações das estruturas de classes das sociedades contemporâneas, resultantes das modificações no processo de acumulação capitalista. Para o autor, a compreensão da dinâmica dos lugares na produção capitalista supõe outra referente aos processos em curso de desconstrução da forma de mercadoria, capaz de apreender a natureza das classes como produto do dever social, resultados de transformações concretas anteriores pelas quais se firmaram as alternativas da história. Referindo-se às classes médias, o autor salienta como estas resultam do processo de separação radical entre os produtores diretos e os instrumentos de trabalho no estágio de desenvolvimento da produção em que, por um lado, a qualificação e a não especialização dos trabalhadores convertem-se em condições sine qua non do trabalho abstrato e, por outro, a consolidação das formas reais de subsunção do trabalho no capital - pela disseminação da maquinaria na produção - já não supõe total coordenação imediata do processo de trabalho, tomando a gerência o lugar do capitalista na função coordenadora do processo produtivo. Resultam assim como oposto da classe dos produtores mercantis simples, definidas como produtoras de trabalhos abstratos cuja aparência é a de trabalhos concretos nãosubstituíveis. Se o valor é o elemento estruturador da sociedade capitalista e de suas classes fundamentais, as classes médias em oposição a essa determinação fundamental estão relacionadas ao surgimento do anti-valor, mecanismo através do qual a reprodução do capital ocorre pelo emprego do fundo público como pressuposto da acumulação privada, e sob condições isentas da concorrência capitalista, inexistindo a formação de uma taxa média de lucro. Por isso, sua emergência política ocorre mediante uma condição de não-representação aparente dos interesses das demais classes, tanto no aparelho do Estado, no exercício das funções próprias da burocracia, quanto nos postos 
de direção dos empreendimentos capitalistas, no papel de dirigentes do processo técnico e social da produção. ${ }^{15}$

Uma última questão nos permitirá, finalmente, concluir a síntese que empreendemos acerca do conceito de classes sociais na tradição marxista. Referimo-nos aqui aos efeitos que o crescimento do número de trabalhadores improdutivos na sociedade moderna ocasiona para a constituição das classes sociais e de seus lugares na produção capitalista. A esse respeito, André Villalobos salienta o caráter datado da obra de Marx que, confrontando-se com o desenvolvimento capitalista do século XIX, não identificava o fenômeno do trabalho improdutivo como relevante para a constituição das classes sociais modernas, menosprezando desse modo a magnitude de sua importância. ${ }^{16}$ Trilhando esse mesmo caminho, Harry Braverman conclui pela inexistência de razões para a distinção dos trabalhos de tipo produtivo e improdutivo, afirmando de maneira demasiado generalizada, que a lógica do capital submete todo o tipo de trabalhadores. ${ }^{17}$ Resta explicar o significado dessa afirmação para os diferentes momentos históricos do desenvolvimento capitalista e como não o faz, Braverman separa os problemas da constituição das classes e da produção do valor na sociedade capitalista, encontrando uma solução teórica para o primeiro, que em última instância abdica dos fundamentos da teoria marxista da sociedade.

\footnotetext{
${ }^{15}$ Isso imputa às classes médias o caráter conservador - e por vezes reacionário - de sua ação política, identificado nos movimentos políticos corporativos que protagonizam. Esses momentos, nos quais as classes médias abandonam sua posição desvinculada (ainda que aparentemente) das contradições capitalistas que permeiam as relações de sociabilidade das classes fundamentais, configuram-se muito mais como insuficiência de seu papel de articuladora dos interesses privados no espaço público do que como constituição de um projeto autônomo de ascensão política.

${ }^{16}$ Cf. RIDENTI, M., op. cit.

${ }^{17}$ BRAVERMAN, Harry. Trabalho e Capital Monopolista : a degradação do trabalho no século XX. 3.ed. Rio de Janeiro: Zahar, 1981.
} 
Por outro lado, as contribuições de Fausto e Oliveira, que sintetizamos, permitem-nos lançar nova luz sobre a solução de Marx para essa questão, atualizando o conteúdo do conceito de classes sociais para a interpretação dos processos históricos do mundo contemporâneo. De fato, Fausto salienta como, para Marx, a forma mercadoria exerce uma dupla e simultânea determinação na produção capitalista corporificada na realização do trabalho produtivo e do trabalho improdutivo e geradora dos seguintes efeitos fundamentais sobre as classes sociais: ${ }^{18}$

1) uma crescente polarização na estrutura da sociedade capitalista contemporânea, em virtude da centralização dos meios de produção e do capital em geral, consubstanciada na absorção dos pequenos produtores independentes pelas classes fundamentais da sociedade;

2) um aumento proporcional dos trabalhadores improdutivos, a medida que se desenvolvem as formas modernas de trabalho baseadas em tecnologia poupadora de mão-de-obra e no crescimento do setor de serviços;

3) o condicionamento do desenvolvimento das classes fundamentais da sociedade pelos dois primeiros efeitos enunciados, sendo a identidade da classe dos capitalistas estabelecida em decorrência da total e definitiva separação entre propriedade e função capitalista, e sendo a identidade dos trabalhadores assalariados modificada pelo aumento do número de trabalhadores improdutivos e por seu complemento, a massificação do trabalho comercial com crescente desqualificação da mão-de-obra ofertada no mercado de trabalho. ${ }^{19}$

\footnotetext{
${ }^{18}$ FAUSTO, R., op. cit.

${ }^{19}$ A respeito da massificação do trabalho comercial na produção contemporânea e de seus efeitos sobre a identidade de classe dos trabalhadores assalariados, Ridenti salienta como o caso dos trabalhadores do comércio constitui um exemplo especial de análise, uma vez que podem ser identificados como trabalhadores improdutivos, mas que muito se aproximam da condição de classe operária, seja porque em
} 
Francisco de Oliveira, por sua vez, salienta como na sociedade de massas, a proliferação da base técnica de não especialização do trabalho e as formas de repressão política sobre a organização sindical dos trabalhadores atuam como fatores negadores da representação das classes subalternas no contexto dos conflitos sociais contemporâneos. Assim, no estágio da acumulação flexível do capital a subsunção real do trabalho no capital resulta no fenômeno da produção de classes destituídas de identidade social. ${ }^{20}$

\section{Um caso especial - as classes sociais no campo}

Essas condições gerais de constituição e luta social das classes no capitalismo contemporâneo, que acima analisamos, produzem seus efeitos sobre a vida social em todos os pólos da produção. Entretanto, tais efeitos ocorrem em cada caso sob condições particulares e com características peculiares, que cabem ao pesquisador desvendar tarefa que, como sabemos, nem sempre se mostra de simples solução. De fato, a despeito de que a tradição sociológica contemporânea possua nas disciplinas particulares da sociologia rural e urbana dois de seus mais consolidados ramos de interpretação da sociedade atual, a constituição do urbano e do rural em objetos particulares de investigação tem variado em sua substância conforme a influência dos matizes teóricos adotados pelos autores que os estudam, disso se originando diferentes e contraditórias abordagens dessas esferas particulares da sociedade global.

seu trabalho prevalece a total separação entre trabalhadores e meio de produção, seja porque a mais-valia resultante da exploração de seu sobretrabalho não se realiza no momento de produção imediata, isto é, na unidade de produção, mas na esfera da circulação, no processo de produção global capitalista. Cf. RIDENTI, M., op. cit. 
O estudo da estrutura de classes no meio rural tem sido concebido sob influência direta dessas abordagens a que nos referimos. De um lado, os teóricos de inspiração funcionalista ao descreverem a oposição entre cidade e campo em termos dualistas conferem à comunidade rural um estatuto particular, atribuindo-lhe uma estrutura social indiferenciada, cuja investigação prescinde da análise das relações de classe, fixando-se essencialmente no estudo dos elementos culturais que a caracterizam. De outro, os autores de tradição dialética insistem na abordagem do problema das classes sociais no campo, compreendendo o desenvolvimento das comunidades rurais como aspecto das transformações em curso na sociedade global capitalista.

Rodolfo Stavenhagen em sua obra - As Classes Sociais nas Sociedades Agrárias - investiga o processo de constituição das classes rurais em sociedades que experimentaram um desenvolvimento capitalista tardio como resultado de sua colonização por sociedades urbano-industriais. O ponto de partida de seu estudo é a refutação da noção de massas rurais indiferenciadas, que dá lugar em sua análise à questão de saber como se desenvolvem as identidades de classes em sociedade, cujo desenvolvimento capitalista ocorre inicialmente no meio rural. A conclusão a que chega é que o estudo das classes sociais rurais requer esclarecer as características de geração e consumo produtivo da propriedade rural nessas sociedades, relacionando-as às formas de integração social e de conflitos que nelas se sucedem. Nesse sentido é que sua definição de campesinato refere-se a uma classe social particular nessas sociedades, que designa uma forma de inserção na produção diversa das classes fundamentais do modo de produção capitalista clássico:

${ }^{20}$ OLIVEIRA, Francisco. "O surgimento do anti-valor : capital, força de trabalho e fundo público". Novos Estudos CEBRAP, n 22, São Paulo, 1988, p. 8-28. 
A estrutura de classes e as estratificações do meio rural dependem dos sistemas econômicos e, em particular, das estruturas agrícolas e dos tipos de empresa agrícola, enquanto unidades econômicas de base. As estruturas agrícolas são complexos sócio-econômicos resultantes, entre outros fatores, das formas dominantes de propriedade e posse da terra e das relações de produção no campo. $(\ldots) .^{21}$

A partir dessa primeira definição genérica, o autor enumera cinco tipos gerais de sistemas de produção agrícola, que varia em razão da forma de propriedade e posse da terra e das relações de produção típica a cada um deles:

1) o sistema de fazenda, caracterizado pela associação de cultivos comerciais a cultivos de subsistência, que dota a unidade de produção de características autárquicas e confere a seus membros formas de sociabilidade atributivas, resultando numa comunidade de baixa mobilidade social;

2) o arrendamento familiar caracterizado pelo uso intensivo de mão-de-obra familiar na exploração dos cultivos, pela elevação do valor de troca das terras objeto de arrendamento, pelo emprego de trabalho intensivo com baixa mecanização como método predominante de cultivo e pelo ciclo agrícola curto, preferindo os arrendatários dedicar-se ao cultivo de culturas cujo retorno possa se dar no mais breve período de tempo;

3) a pequena propriedade familiar, cuja produção destina-se a garantir a reprodução social de seus membros, nela combinando-se grande esforço de produção de gêneros de subsistência com limitada quantidade de produtos destinados à comercialização;

4) a agricultura de plantação (ou plantation) caracterizada pela utilização de trabalho intensivo e de mão-de-obra barata - assalariada ou escrava - para a exploração de

${ }^{21}$ STAVENHAGEN, R., op. cit., p. 68. 
cultivos comerciais, e que nos países possuidores de fronteiras agrícolas de colonização formou-se em confronto direto com a pequena propriedade familiar e com os regimes flexíveis de posse de terra, ocupando sob a forma de propriedade privada individual as regiões onde predominavam essas formas anteriores de propriedade da terra;

5) a agricultura capitalista extensiva que utiliza o emprego exclusivo de força de trabalho assalariada, geralmente praticada sob condições de baixo preço das terras e alto preço da mão-de-obra, o que a faz optar pelo emprego flutuante e sazonal da força de trabalho recrutada.

Em torno dessas cinco modalidades de organização do empreendimento agrícola capitalista nas sociedades investigadas é que o autor pretende elaborar o conceito de campesinato de que se vale para referir-se às classes rurais nelas encontradas. Desse modo, o conceito de campesinato que enuncia requer para converter-se de categoria genérico-abstrata em categoria histórica, o estudo das formas particulares através das quais se desenvolve a produção capitalista na agricultura, nele encontrando-se expressas as formas de vinculação com a terra, os tipos de racionalidade econômica e as relações sociais predominantes em cada uma dessas formas. A diferenciação camponesa resulta, então como aspecto do desenvolvimento desigual da agricultura nas diversas sociedades, ou regiões de uma mesma sociedade capitalista, e expressa as alternativas histórico-concretas que essas sociedades e regiões experimentaram no decorrer de sua evolução. $^{22}$

Paulo Sandroni, embora partindo de problemas diferentes dos de Stavenhagen, conclui de modo similar acerca da estrutura de classes sociais rurais na sociedade capitalista. Para esse autor, entretanto, o campesinato constitui classe intermediária do 
modo de produção capitalista e suas alternativas históricas de desenvolvimento giram em torno das possibilidades de diferenciação que tornam parte dos seus membros produtores capitalistas, e converte o restante em proletários rurais. ${ }^{23}$ Desse modo, o campesinato apenas subsiste naquelas regiões onde a produção capitalista ainda não chegou a instalar-se completamente - zonas de fronteira agrícola em que a exploração comercial do solo coexiste com o regime da produção familiar ou em regiões agrícolas pouco desenvolvidas nas quais o aporte de capitais e a exploração econômica do solo baseiam-se ainda em formas tradicionais de cultivo, tendendo à dissolução quando do advento de um processo de modernização capitalista que resulte em reestruturação das formas de exploração do solo e em constituição de um mercado de trabalho rural.

Confrontando as duas perspectivas de análise acima sintetizadas, parece-nos ser a de Stavenhagen a mais adequada à compreensão do desenvolvimento capitalista na agricultura. Nela, as relações de classe no meio rural das sociedades capitalistas não aparecem apenas como reflexo das determinações existentes na sociedade global, mas dotadas de uma dinâmica particular. Como exemplo devemos relembrar, a análise de Verena Stolcke que interpretou a instituição do colonato na agricultura brasileira como produto das lutas de classe empreendidas entre os trabalhadores e os proprietários rurais no período inicial de constituição do mercado de trabalho livre no país, que tornaram inadequadas as modalidades de contrato de locação de serviços e da parceria, ocasionando o surgimento de uma nova relação de trabalho que combinava, por um lado, o cultivo de gêneros de subsistência e de comercialização com modalidades de remuneração fixa e variável da força de trabalho e, por outro, formas de controle

${ }^{22}$ Ic., ibid. 
internas e exógenas ao núcleo familiar de produção; ${ }^{24}$ De acordo com o mesmo raciocínio, José Flávio Bertero insiste na análise da configuração de classe do parceiro, considerando-o em oposição ao proletário rural prestamista de força de trabalho e de capital, portador de uma dupla personificação social, que auferindo-lhe a condição de "sócio da produção" produz a ideologia da comunhão de seus interesses com a classe dos proprietários rurais em torno da qual sustenta-se sua perspectiva de realização de uma acumulação particular com a conseqüente transformação de sua condição de classe. Igualmente para este último autor, o produtor integrado tem sua situação de classe determinada pelo capital industrial, diferenciando-se tanto do proletário quanto do parceiro, e possuindo, a despeito da convergência de interesses agrários que caracteriza sua relação com os demais setores do campesinato, uma determinação específica em sua identidade social em razão de sua condição de subsunção ao capital industrial. ${ }^{25} \mathrm{E}$ finalmente, Bernardo Sorj refere-se às relações de interação política entre as classes sociais no campo, destacando a heterogeneidade de suas identidades sociais e os efeitos adversos resultantes da homogeneização e diferenciação artificiais, comumente presentes nas políticas governamentais de desenvolvimento rural:

(...) Uma questão central que afeta o sindicalismo rural é a própria estrutura da classe operária no campo, altamente heterogênea, na qual o assalariado se confunde com o minifundista, já que o assalariado temporário ainda é uma figura central no campo. Dentro desse contexto, uma estrutura sindical que represente especificamente o setor dos assalariados se confronta com as manipulações do Governo, que ora procura

\footnotetext{
${ }^{23}$ SANDRONI, P. Questão Agrária e Campesinato : a funcionalidade da pequena produção mercantil. São Paulo: Polis, 1980. (coleção Teoria e História, 9).

${ }^{24}$ STOLCKE, V. Cafeicultura: homens, mulheres e capital (1850-1980). São Paulo, Brasiliense, 1986.

25 BERTERO, J. F. Parceiros do Rio Pardo: um estudo do processo de trabalho na cultura da cebola. Dissertação de Mestrado. Campinas, 1983, mimeo.
} 
unificar diferentes camadas, anulando as suas diferenças, ora as diferencia totalmente de forma artificial. ${ }^{26}$

\section{Considerações Finais}

A partir da gênese do conceito de classes sociais no pensamento de Karl Marx, buscamos neste trabalho explanar o desenvolvimento de seus diferentes sentidos, segundo a formulação de autores clássicos e contemporâneos. Assim procedendo, pretendemos evidenciar como tal conceito para além de uma representação abstrata da estrutura social, adquire na tradição marxista o caráter de categoria mediadora: expressa, desde sua proposição, à dinâmica de contradições próprias das sociedades em que tem lugar a dominação política e a exploração econômica do trabalho alheio - e, nesse sentido, somente podemos definir uma classe em função do conflito necessário que estabelece com sua homóloga oposta no curso da história.

Ao estudarmos o caso particular das classes no campo, restringimos nossa análise à época capitalista. Em todos os exemplos elencados tomamos o desenvolvimento capitalista no campo como processo histórico contraditório, resultante das relações de antagonismos protagonizadas pelas classes sociais em luta. Desse modo, a forma final dos processos de modernização capitalista da agricultura, que nesse estudo referimos, pode ser descrita em relação ao grau de hegemonia alcançado pelas classes dominantes que logram programar, ora mediante a imposição, ora mediante a negociação política, os projetos de transformação política e social de que são portadoras

${ }^{26}$ SORJ, B. Estado e Classes Sociais na Agricultura Brasileira. 2.ed. Rio de Janeiro: Guanabara, 1984. 
- mas não sem antes incorporar a eles respostas para as demandas políticas das classes com que se defrontam.

(col. Agricultura e Sociedade). 